12. Saga, Y et al. Mice develop normally without tenascin. Genes Dev. 6, 1821-1831 (1992).

13. Yang, Y. et al. Functional redundancy of the muscle-specific transcription factors Myf5 and myogenin. Nature 379, 823-825 (1996)

14. Joyner, A. L. et al. Subtle cerebellar phenotype in mice homozygous for a targeted deletion of the En-2 homeobox. Science 251, 1239-1243 (1991).

15. Laney, J. D. \& Biggin, M. D. Redundant control of Ultrabithorax by zeste involves functional levels of zeste protein binding at the Ultrabithorax promoter. Development 122, 2303-2311 (1996).

16. Schorle, H. et al. Development and function of T cells in mice rendered interleukin-2 deficient by gene targeting. Nature 352, 621-624 (1991).

17. Taniguchi, T. Cytokine signaling through nonreceptor protein tyrosine kinases. Science 268, 251-255 (1995).

18. Steindler, D. A. et al. Tenascin Knockout Mice: Barrels, Boundary Molecules, and Glial Scars. J. Neurosci. 15, 1971-1983 (1995).

19. Pekny, M. et al. Mice lacking glial fibrallary acidic protein display astrocytes devoid of intermediate filaments but develop and reproduce normally. EMBO J. 14, 1590-1598 (1995).

20. Reed, S. I. G1-specific cyclins in search of an S-phase promoting factor. Trends Genet. 7, 95-99 (1991)

21. Roche, S. et al. Requirement for Src family protein tyrosine kinases in G-2 for fibroblast cell division. Science 269, 1567-1569 (1995).

22. Fisher, R. A. The sheltering of lethals. Am. Nat 69, 446-455 (1935).

23. Christiansen, F. B. \& Frydenberg, O. Selection-mutation balance for two nonallelic recessives producing an inferior double homozygote. Am. J. Hum. Genet. 29, 195-207 (1977).

24. Bailey, G. S. et al. Gene duplication in tetraploid fish: model for gene silencing at unlinked loci. Proc Natl Acad. Sci. USA 75, 5575-5579 (1978).

25. Allendorf, F. W. Protein polymorphism and the rate of loss of duplicate gene expression. Nature 272, $76-78(1978)$

26. Kimura, M. \& King, J. L. Fixation of a deleterious allele at one of two duplicate loci by mutation pressure and random drift. Proc. Natl Acad. Sci. USA 76, 2858-2861 (1979).

27. Li, W.-H. Rate of gene silencing at duplicate loci: a theoretical study and interpretation of data from tetraploid fish. Genetics 95, 237-258 (1980)

28. Ohta, T. Time for spreading of compensatory mutations under gene duplication. Genetics 123, 579584 (1989).

29. Li, X. \& Noll, M. Evolution of distinct developmental functions of three Drosophila genes by acquisition of different cis-regulatory regions. Nature 367, 83-87 (1994).

30. Krakauer, D. C. \& Pagel, M. Selection by somatic signals. Phil. Trans. R. Soc. Lond. B 351, 647-658 (1996).

Acknowledgements. We thank D. Krakauer and K. Sigmund for discussion. This work was supported by the Wellcome Trust (M.A.N.) and the European Community (M.C.B.)

Correspondence should be addressed to M.A.N. (e-mail: martin.nowak@zoo.ox.ac.uk).

\section{Distinct cortical areas associated with native and second languages}

Karl H. S. Kim ${ }^{\star}$, Norman R. Relkin $\dagger$, Kyoung-Min Lee ${ }^{\star} \&$ Joy Hirsch ${ }^{\star} \dagger$

Department of Neurology, ${ }^{*}$ Memorial Sloan-Kettering Cancer Center,

1275 York Avenue, New York, New York 10021, USA

$\dagger$ Department of Neurology and Neuroscience, Cornell University Medical College, 1300 York Avenue, New York, New York 10021, USA

The ability to acquire and use several languages selectively is a unique and essential human capacity. Here we investigate the fundamental question of how multiple languages are represented in a human brain. We applied functional magnetic resonance imaging (fMRI) to determine the spatial relationship between native and second languages in the human cortex, and show that within the frontal-lobe language-sensitive regions (Broca's area) ${ }^{1-3}$, second languages acquired in adulthood ('late' bilingual subjects) are spatially separated from native languages. However, when acquired during the early language acquisition stage of development ('early' bilingual subjects), native and second languages tend to be represented in common frontal cortical areas. In both late and early bilingual subjects, the temporal-lobe languagesensitive regions (Wernicke's area) ${ }^{1-3}$ also show effectively little or no separation of activity based on the age of language acquisition. This discovery of language-specific regions in Broca's area advances our understanding of the cortical representation that underlies multiple language functions.

Indirect evidence for topographic specialization within the language-dominant hemispheres of multilingual subjects has been provided by clinical reports of selective impairments in one or more of several languages as a result of surgery involving the left perisylvian area ${ }^{4}$. Multilingual patients with complex partial seizure disorders of temporal lobe origin have been reported to shift from a primary to a second language together with ictal progression ${ }^{5}$. Different languages have also been selectively disrupted in polyglots by electrical stimulation of discrete regions of the neocortex of the dominant hemisphere ${ }^{6,7}$. Changes in the topography of background electroencephalogram (EEG) coherence obtained during translation tasks also suggest spatial separation of cortical regions involved in multiple languages ${ }^{8}$. Although these reports are consistent with the existence of spatially separate representations for each language, such functions have not been localized.

Silent, internally expressive linguistic tasks were performed in two languages by subjects who either acquired conversational fluency in their second languages as young adults ('late' bilinguals) or who acquired two languages simultaneously early in their development ('early' bilinguals) (Table 1). As Broca's and Wernicke's areas are known to perform central roles in human language functions ${ }^{1-3,9-12}$, we have focused our observations on these cortical areas.

The main findings for a typical 'late' bilingual subject (subject (A)) are shown in Fig. 1. The anterior language area is highlighted by the green box and shown expanded in the inset. Red indicates significant activity during the native language task (English), whereas yellow indicates activity associated with the second language task (French). Two distinct but adjacent centres of activation $(+)$ separated by $\sim 7.9 \mathrm{~mm}$ were evident within the inferior frontal gyrus, suggesting that two specific regions served each of the two languages. In the posterior language area of the same subject (Fig. 2 ), the same tasks yielded centroids of activity with a centre-tocentre spacing of $1.1 \mathrm{~mm}$, less than the width of a voxel, suggesting that similar or identical cortical regions served both languages in this posterior area.

For all six late bilingual subjects, distinct areas of activation were observed for the native and second languages in Broca's area (Table $2 \mathrm{a}$ and Fig. 3). The separation between centroids of activity ranged from $\sim 4.5 \mathrm{~mm}$ to $9.0 \mathrm{~mm}$ within one slice, and the number of voxels for each language was similar for each subject. On the other hand, activity in Wernicke's area (Table 2b) showed centre-to-centre distances between the centre-of-mass centroids ranging from 1.1 to $2.8 \mathrm{~mm}$. The mean centroid distance between the anterior

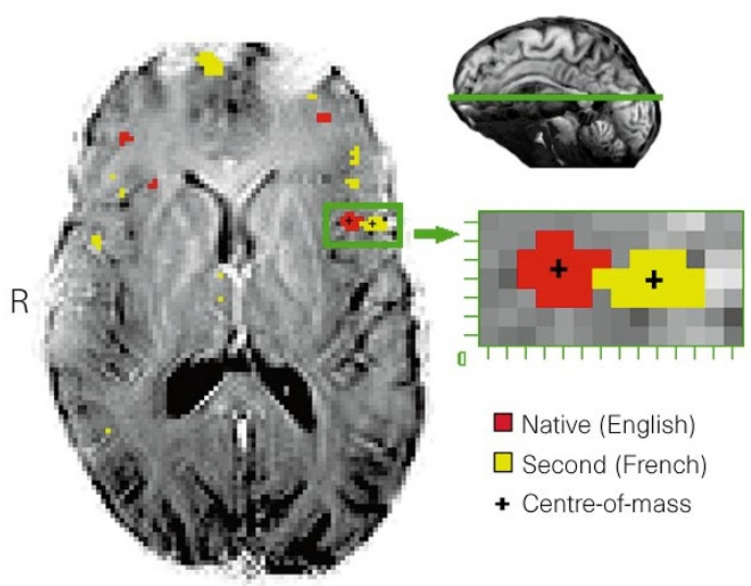

Figure 1 A representative axial slice from a 'late' bilingual subject $(A)$ shows all voxels that pass the multistage statistical criteria at $P \leq 0.0005$ as either red (native language) or yellow (second acquired language). An expanded view of the pattern of activity in the region of interest (inferior frontal gyrus, Brodmann's area 44 (refs 2, 3, 18), corresponding to Broca's area ${ }^{1-3}$ ) indicates separate centroids (+) of activity for the two languages. Centre-of-mass calculations indicate that the centroids are separated on this plane by $7.9 \mathrm{~mm}$. The green line on the upper right mid-sagittal view indicates the plane location. $R$ indicates the right side of the brain. 


\begin{tabular}{|c|c|c|c|c|c|c|}
\hline Subject & Age & Gender & Native language(s) & Second language & Handedness & Laterality quotient ${ }^{24}$ \\
\hline$A$ & 31 & M & English & French & Right & 60 \\
\hline B & 32 & $M$ & Korean & English & Right & 100 \\
\hline $\mathrm{C}$ & 28 & M & Korean & English & Right & 86 \\
\hline D & 26 & $M$ & English & Japanese & Ambidextrous & -20 \\
\hline$E$ & 27 & $\mathrm{~F}$ & Spanish & English & Right & 100 \\
\hline $\mathrm{F}$ & 32 & $\mathrm{~F}$ & German & English & Right & 60 \\
\hline $\mathrm{G}$ & 38 & $\mathrm{~F}$ & Turkish/English & NA & Ambidextrous & -27 \\
\hline $\mathrm{H}$ & 27 & $M$ & English/Hebrew & NA & Right & 85 \\
\hline | & 23 & M & English/Spanish & NA & Right & 100 \\
\hline J & 24 & $\mathrm{~F}$ & Croatian/English & NA & Right & 89 \\
\hline K & 31 & $M$ & Italian/German & NA & Right & 90 \\
\hline L & 32 & M & Chinese/English & NA & Ambidextrous & 24 \\
\hline
\end{tabular}

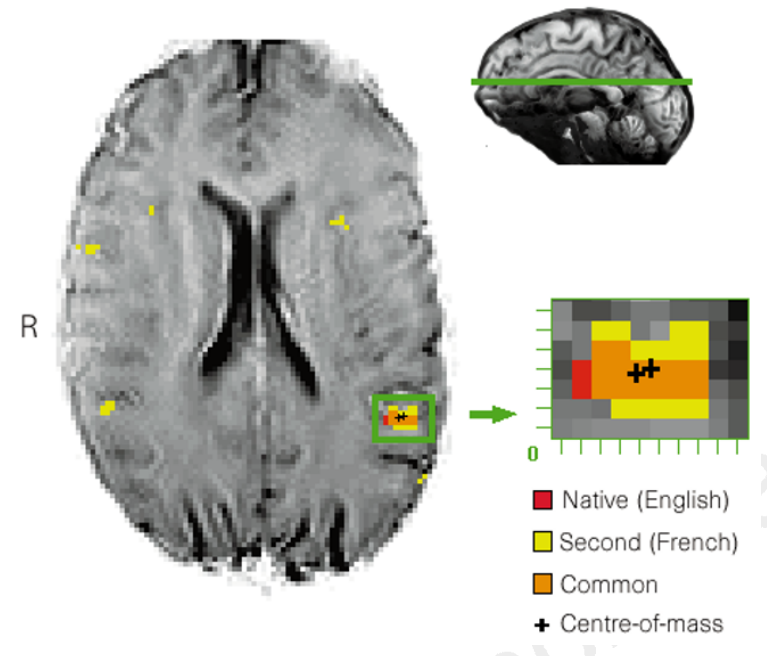

Figure 2 Similar to Fig. 1, an expanded view of the pattern of activity within the superior temporal gyrus (Brodmann's area 22 (refs 2, 3, 18), corresponding to Wernicke's area ${ }^{1-3}$ ) indicates centroids of activity for the two languages in this posterior language region. Orange indicates that the voxels that passed all statistical criteria during both the native and acquired language tasks. Centreof-mass calculations indicate that the centroids are separated on this plane by $1.1 \mathrm{~mm}$, less than the diameter of a single voxel.

language areas was $6.43( \pm 1.83) \mathrm{mm}$ and exceeded that of the posterior language areas, which was $1.88( \pm 0.62) \mathrm{mm}$, for these subjects $(t=5.43$, d.f. $=5, P \leq 0.004)$.

The overall stability of the centre-of-mass centroids with variation in the level of statistical stringency (probability of a falsepositive result, $P$ ) is illustrated for subject (A) in Fig. 4. In the case of the anterior language area, the centre-to-centre distance between the centroids of activity associated with each language remained within the range of 7.8 to $9.1 \mathrm{~mm}$ over statistical stringency levels from $P \leq 0.0002$ to $P \leq 0.02$. In the case of the posterior language area, the centroids remained within the approximate width of one voxel, $1.6 \mathrm{~mm}$, over the same range of stringency levels. Similar results were obtained for all subjects, confirming that threshold criteria do not account for the centre-to-centre distances between centroids of activity associated with each language task.

Figure 5 illustrates the main findings for a typical 'early' bilingual subject (subject $(\mathrm{G})$ ) for whom the centre-to-centre distance between the activity centroids ( + ) of the two activity patterns was $2.3 \mathrm{~mm}$, less than 1.5 voxels (Table $2 \mathrm{a}$ ). This represents the general pattern for all six early bilingual subjects, where the mean separation
Figure 3 Expanded views of the activity patterns within Brodman's area 44 (and 46 (refs 2, 3, 18), subject B) for each 'late' bilingual subjects (A-F) indicate the active regions during the native language task (red) and the second acquired language task (yellow). The level of statistical stringency (probability of a false positive result, $P$ ) was $\leq 0.0005$ for each subject. The centre-of-mass is indicated by a plus sign for each language; area and centre-to-centre $(\mathrm{C}-\mathrm{C})$ distances are listed in Table 2a.

was $1.53( \pm 0.78) \mathrm{mm}$. In the case of the posterior language area, Wernicke's area, the mean separation for all early bilingual subjects was $1.58( \pm 0.79) \mathrm{mm}$, similar to the anterior area.

Our findings are summarized by an analysis of variance (Table 3 ) in which language area (Broca's and Wernicke's) was compared with bilingual type (early and late) with respect to the centre-to-centre distance in millimetres between the two language centroids. Significant main effects for language area $(P \leq 0.000059)$ and bilingual type $(P \leq 0.000084)$ with an interaction effect $(P \leq 0.000067)$ show that activation sites for the two different languages tend to be spatially distinct in Broca's area when the second language was obtained late in life and not when acquired in early childhood; and

\begin{tabular}{lcrrrc}
\hline Table 3 ANOVA & \multicolumn{7}{c}{ MS } & $F$ & $P$ \\
\hline Source of variation & SS & d.f. & MS & & \\
A (language area) & 52.01 & 1 & 52.01 & 25.70 & 0.000059 \\
B (bilingual type) & 48.80 & 1 & 48.80 & 24.11 & 0.000084 \\
AB & 50.79 & 1 & 50.79 & 25.10 & 0.000067 \\
Within cell & 40.47 & 20 & 2.02 & &
\end{tabular}




\begin{tabular}{|c|c|c|c|c|c|c|c|c|c|c|c|}
\hline \multicolumn{12}{|c|}{ (a) Anterior language area } \\
\hline \multirow[b]{2}{*}{ Subject } & \multirow[b]{2}{*}{ Bilingual type } & \multirow[b]{2}{*}{ Hemisphere } & \multirow[b]{2}{*}{ Gyrus } & \multirow{2}{*}{$\begin{array}{l}\text { Brodmann's } \\
\text { area }\end{array}$} & \multicolumn{3}{|c|}{$\begin{array}{l}\text { Talairach \&Tournoux } \\
\text { sectors }^{18 \star}\end{array}$} & \multirow{2}{*}{$\begin{array}{l}\text { Area } L 1 \dagger \\
\left(\mathrm{mm}^{2}\right)\end{array}$} & \multirow{2}{*}{$\begin{array}{l}\text { Area } \mathrm{L}_{2} \dagger \\
\left(\mathrm{mm}^{2}\right)\end{array}$} & \multirow{2}{*}{$\begin{array}{l}\text { C-C distance } \ddagger \\
(\mathrm{mm})\end{array}$} & \multirow{2}{*}{$\begin{array}{c}\text { Common voxels } \\
\text { L1 and L2† } \\
(\%)\end{array}$} \\
\hline & & & & & $X$ & Y & Z & & & & \\
\hline A & Late & Left & Inferior frontal & 44 & $d$ & $\mathrm{D}$ & 12 & 34.2 & 34.2 & 7.9 & 0 \\
\hline$B$ & Late & Left & Inferior frontal & 44,46 & $c$ & $D, C$ & 12 & 14.6 & 12.2 & 4.5 & 0 \\
\hline $\mathrm{C}$ & Late & Left & Inferior frontal & 44 & $c$ & D & 12 & 12.2 & 14.6 & 9.0 & 0 \\
\hline$C^{\prime}$ & Late & Left & Inferior frontal & 44 & $\mathrm{C}$ & $\mathrm{D}$ & 12 & 15.4 & 24.2 & 7.5 & 0 \\
\hline $\mathrm{D}$ & Late & Left & Inferior frontal & 44 & C & $\mathrm{B}$ & 1 & 12.2 & 17.1 & 4.7 & 0 \\
\hline$E$ & Late & Left & Inferior frontal & 44 & $c$ & $\mathrm{D}$ & 12 & 12.2 & 12.2 & 7.0 & 0 \\
\hline $\mathrm{F}$ & Late & Left & Inferior frontal & 44 & c & $\mathrm{D}$ & 12 & 33.1 & 19.8 & 11.2 & 0 \\
\hline $\mathrm{G}$ & Early & Left & Interior frontal & 44 & $\mathrm{C}$ & $\mathrm{D}$ & 12 & 107.4 & 75.7 & 2.3 & 50 \\
\hline $\mathrm{H}$ & Early & Left & Interior frontal & 44 & $c$ & $\mathrm{D}$ & 12 & 12.2 & 7.3 & 0.5 & 60 \\
\hline I & Early & Left & Interior frontal & 44 & $c$ & $\mathrm{~B}$ & 1 & 41.9 & 28.6 & 0.7 & 46 \\
\hline J & Early & Left & Interior frontal & 44 & c & $\mathrm{D}$ & 12 & 8.8 & 4.4 & 1.7 & 20 \\
\hline K & Early & Left & Interior frontal & 44 & $c$ & $\mathrm{D}$ & 12 & 123.4 & 154.2 & 2.2 & 45 \\
\hline $\mathrm{L}$ & Early & Left & Interior frontal & 44 & c & $\mathrm{D}$ & 12 & 44.1 & 17.6 & 1.8 & 22 \\
\hline \multicolumn{12}{|c|}{ (b) Posterior language area } \\
\hline$A$ & Late & Left & Superior temporal & 22 & $d$ & $G$ & 20 & 39.1 & 65.9 & 1.1 & 48 \\
\hline B & Late & Left & Superior temporal & 22 & d & $\mathrm{G}$ & 20 & 9.8 & 19.5 & 1.5 & 33 \\
\hline C & Late & Left & Superior temporal & 22 & d & $\mathrm{F}$ & 8 & 31.7 & 34.2 & 2.2 & 35 \\
\hline$C^{\prime}$ & Late & Left & Superior temporal & 22 & $d$ & $\mathrm{G}$ & 20 & 19.8 & 33.1 & 3.3 & 26 \\
\hline $\mathrm{D}$ & Late & Left & Superior temporal & 22 & d & $\mathrm{E}$ & 1 & 43.9 & 19.5 & 2.2 & 30 \\
\hline $\mathrm{E}$ & Late & Left & Superior temporal & 22 & d & $\mathrm{F}$ & 8 & 22.0 & 9.8 & 1.5 & 18 \\
\hline $\mathrm{F}$ & Late & Left & Superior temporal & 22 & d & G & 16 & 83.7 & 46.3 & 1.0 & 18 \\
\hline $\mathrm{G}$ & Early & Left & Superior temporal & 22 & d & $\mathrm{G}$ & 16 & 4.9 & 31.7 & 1.7 & 15 \\
\hline $\mathrm{H}$ & Early & Left & Superior temporal & 22 & d & $\mathrm{F}$ & 16 & 56.2 & 39.1 & 1.5 & 56 \\
\hline I & Early & Left & Superior temporal & 22 & d & $E$ & 4 & 94.7 & 22.0 & 3.0 & 23 \\
\hline j & Early & Left & Superior temporal & 22 & d & $\mathrm{F}$ & 16 & 15.4 & 125.6 & 1.4 & 12 \\
\hline K & Early & Left & Superior temporal & 22 & d & $G$ & 20 & 121.2 & 96.9 & 1.3 & 62 \\
\hline $\mathrm{L}$ & Early & Left & Superior temporal & 22 & d & $\mathrm{F}$ & 12 & 48.5 & 88.1 & 0.6 & 48 \\
\hline
\end{tabular}

$\mathrm{C}^{\prime}$ is a replication of $\mathrm{C}$ after 16 months on a different scanner. All observations of area and distance are made at a common level of significants $(P \leq 0.0005)$.

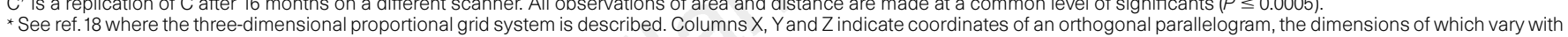
the principal axes of the brain. Each of these volumes is defined by its three dimensions indicated by a capital letter ( $Y$ ), a lower-case letter (X), and a number (Z).

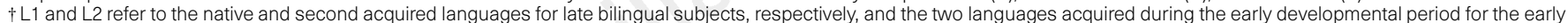
bilingual subjects in the respective order as listed on Table 1.

$\ddagger \mathrm{C}$-C distance refers to the centre-to-centre spacing between the centre-of-mass centroids of significant voxels associated with the two languages

that Wernicke's area showed little or no separation of activity regardless of age of acquisition.

The observation that the anatomical separation of the two languages in Broca's area varies with the time at which the second language was acquired, suggests that age of language acquisition may be a significant factor in determining the functional organization of this area in human brain. Human infants, initially capable of discriminating all phonetically 'relevant' differences, may eventually modify the perceptual acoustic space, based on early and repeated exposure to their native languages ${ }^{13}$. It is possible that representations of languages in Broca's area that are developed by exposure early in life are not subsequently modified. This could necessitate the utilization of adjacent cortical areas for the second language learned as an adult.

The difference between the results of this investigation and a positron emission tomography (PET) study in which multiple languages were found to generate overlapping regions of activation within the inferior frontal gyrus ${ }^{14}$ may be reconciled in part by the higher effective resolution of this fMRI technique. The intrinsic resolution of the PET $\mathrm{H}_{2}{ }^{15} \mathrm{O}$ cerebral-blood-flow technique was $5 \times 5 \times 6 \mathrm{~mm}^{3}$ and the results from several subjects were combined and averaged. Individual variability in both the locations of the language areas and the diversity of brain shapes and gyral patterns of the subjects averaged together further reduce the effective resolution of this approach ${ }^{9,15}$, which could account for the discrepancy. However, on the basis of our findings, the distinction between native and second languages may be less for younger ages of exposure to a second language. The average age of initial exposure to the second language in the PET study was 7.3 years, younger than that of the late bilingual subjects in our study, and could therefore be consistent with our observation for early bilinguals.

To render our findings independent of particular languages or cultural background, our study made use of simple expressive tasks with similar semantic content across multiple languages and

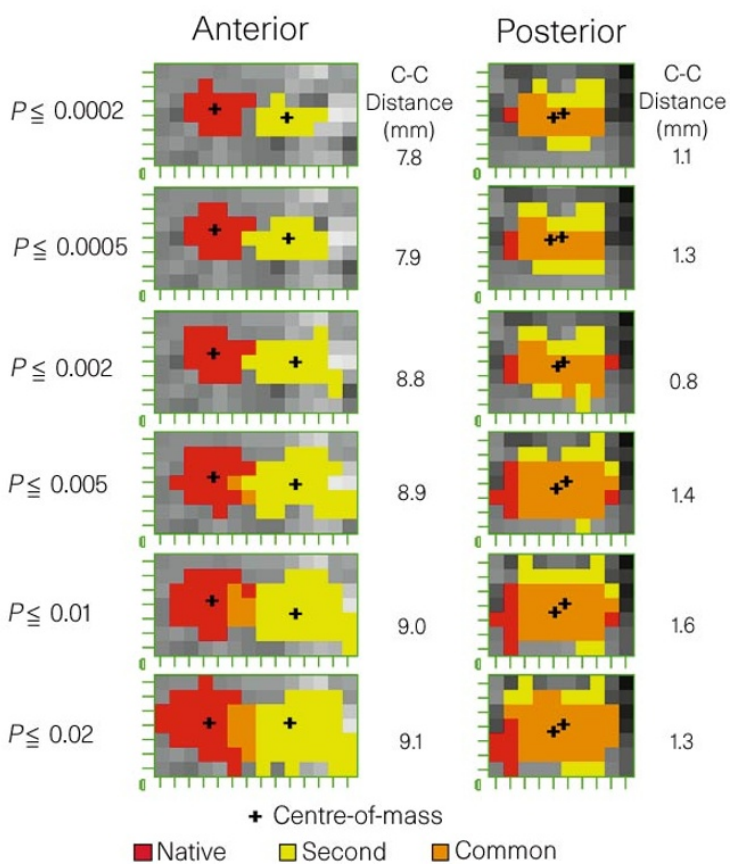

Figure 4 All voxels that pass the statistical criteria during the native (red) and acquired (yellow) language tasks (subject (A)) are shown for the anterior region of interest, left, and the posterior region of interest, right, over approximately 3 orders of statistical stringency $(P \leq 0.0002$ to $P \leq 0.02)$. The centre-to-centre $(\mathrm{C}-\mathrm{C})$ distance between the centroids of activity in the anterior area (based on the centre-of-mass, +), ranges from $7.8 \mathrm{~mm}$ at $P \leq 0.0002$ to $9.1 \mathrm{~mm}$ at $P \leq 0.02$, suggesting that the centroid is nearly independent of cluster size (radial expansion). Similarly, for the posterior language area, the $\mathrm{C}-\mathrm{C}$ distance ranges from 1.1 to $1.3 \mathrm{~mm}$ (less than the width of a single voxel) over the same level of statistical stringency. 


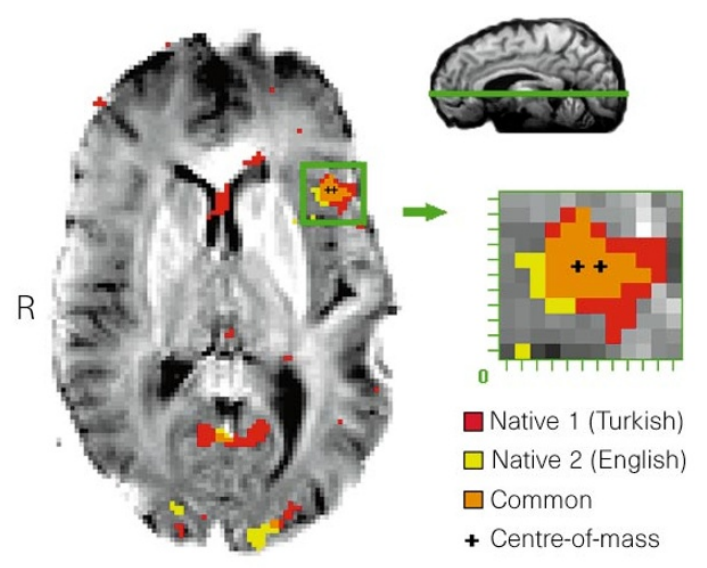

Figure 5 A representative axial slice from an 'early' bilingual subject $(G)$ who learned English and Turkish simultaneously during early childhood shows all voxels that pass the multistage statistical criteria at $P \leq 0.0005$. Red indicates the Turkish language task and yellow indicates the English language task. An expanded view of the region of interest (Broca's area ${ }^{1-3}$ ) indicates multiple common voxels between the two language areas. The geometric centres-ofmass indicate that the centroids are within 1.5 voxels. $R$ indicates the right side of the brain.

included subjects with various combinations of languages (Table 1). Our findings are consistent with distinct roles for the anterior and posterior language areas in the processing of human language, and raise further questions regarding the role of Broca's area in processing the phonetic structures of different languages.

\section{Methods}

Imaging. A 1.5-tesla magnetic resonance scanner (General Electric) retrofitted (advanced NMR Instascan) for echo-planar imaging and subsequently upgraded to the GE echo-planar system was used to obtain $\mathrm{T}^{\star}$-weighted images with a gradient echo pulse sequence (echo time, $60 \mathrm{~ms}$; repetition time, $3,000 \mathrm{~ms}$; flip angle, $30^{\circ}$ ) which is sensitive to magnetic resonance signal changes caused by alteration in the proportion of deoxyhaemoglobin in the local vasculature accompanying neuronal activation ${ }^{16}$. Either a volumeoptimized $5 \times 5$-mesh dome resonator ${ }^{17}$ or a General Electric head coil was employed. The in-plane resolution was $1.6 \mathrm{~mm}$ by $1.6 \mathrm{~mm}$. Slice thickness was $4.5-4.7 \mathrm{~mm}$ and 16 contiguous slices of brain were obtained parallel to a reference line through the superior edge of the anterior commissure and the inferior edge of the posterior commissure ${ }^{18,19}$. These slices covered the inferior frontal gyrus (the anterior language region, 'Broca's' area including Brodmann's areas 44 and 46) and the posterior superior temporal gyrus (the posterior language region, 'Wernicke's' area including Brodmann's area $22)^{1-3,18,19}$. Thirty images were taken, one every $3 \mathrm{~s}$; thus, an entire run lasted $90 \mathrm{~s}$. The first 10 images ( $30 \mathrm{~s}$ ) were acquired during a baseline period, followed by a stimulation or task period of 10 images ( $30 \mathrm{~s})$, and a final (30 s) baseline period also consisting of 10 images. A fixation cross-hair was provided during the baseline epochs to help the subject to maintain a stable head position.

Analysis. Two identical runs were performed in each language. Before statistical analysis, all brain images were computationally aligned to allow direct spatial comparisons between different language tasks for individual subjects $^{20}$, and a two-dimensional gaussian filter (approximately 3 volume elements, voxels, at half-height) was applied to the data. Significant signal changes were identified by a multistage statistical analysis which compared average baseline and stimulation signal intensities and required significant signal changes on two runs (coincidence) ${ }^{21,22}$. The rate of false-positive voxels, $p$, was empirically determined from images of a copper sulphate solution-filled spherical phantom (General Electric standard) and found to be less than 0.0005 . The centroid of a cluster of language-activated voxels was determined as the two-dimensional centre of mass, and the centre-to-centre distance between centroids was taken as the separation $(\mathrm{mm})$ between language-specific activity. Task. The sentence-generation task was performed silently (internal speech) to minimize head movement and was similar to tasks previously employed in neuroimaging language studies ${ }^{23}$. The subject was instructed to "describe" events that occurred during a specified period of the previous day (morning, afternoon, night); this task was practised before the imaging sessions. Immediately before each run, the subject was instructed which language he/she was to imagine speaking, and graphical cues signalling morning, afternoon, and night were displayed in various orders for $10 \mathrm{~s}$ during the 30 -s task period. These graphics provided common non-linguistic cues for the task and the unpredictable order of presentation presumably reduced the tendency to rehearse mentally before the cue. The languages were alternated during the imaging session to prevent habituation and a potentially time-dependent bias.

Subjects. Twelve healthy multilingual volunteers, 9 males and 3 females, were recruited according to institutional informed consent procedures. Subjects were either right-handed or ambidextrous, as assessed by the Edinburgh handedness inventory ${ }^{24}$ (Table 1). The mean age of subjects was $29.3( \pm 4.2)$ years. Six subjects ('early' bilinguals) were exposed to two languages during infancy, and six subjects ('late' bilinguals) were exposed to a second language in early adulthood. The mean age of initial exposure to the second language was $11.2( \pm 1.5)$ years and the mean age that conversational fluency was achieved was 19.2 ( \pm 4.1$)$ years. Each of the 'late' bilingual subjects had lived in the country of the second language, which assured a high standard for fluency. Each of the early bilinguals was raised in a home where either the parents spoke one language and siblings and friends spoke another, or the parents spoke two languages. Ten languages were represented as indicated on Table 1, and all subjects reported approximately equal fluency and frequent usage in each language at the time of testing.

Received 20 February; accepted 30 April 1997.

1. Geschwind, N. The organization of language and the brain. Science 170, 940-944 (1970).

2. Kretschmann, H.-J. \& Weinrich, W. Cranial Neuroimaging and Clinical Neuroanatomy 2nd edn (Thieme Medical, New York, 1992).

3. Damasio, H. \& Damasio, A. Lesion Analysis in Neuropsychology (Oxford Univ. Press, New York, 1989).

4. Gomez-Tortosa, E. et al. Selective deficit of one language in a bilingual patient following surgery in the left perisylvian area. Brain Lang. 48, 320-325 (1995).

5. Schwartz, M. S. Ictal language shift in a polyglot. J. Neurol. Neurosurg. Psychiat. 57, 121 (1994).

6. Ojemann, G. A. Brain organization for language from the perspective of electrical stimulation mapping. Behav. Brain Sci. 6, 189-230 (1983).

7. Black, P. M. \& Ronner, S. F. Cortical mapping for defining the limits of tumor resection. Neurosurgery 20, 914-919 (1987).

8. Petsche, H., Etlinger, S. C. \& Filz, O. Brain electrical mechanisms of bilingual speech management: an initial investigation. Electroencephalogr. Clin. Neurophysiol. 86, 385-394 (1993).

9. Démonet, J. F., Wise, R. \& Frackowiak, R. S. Language functions explored in normal subjects by positron emission tomography: A critical review. Human Brain Mapping 1, 39-47 (1993).

10. Zatorre, R. On the representation of multiple languages in the brain: Old problems and new directions. Brain and Language 36, 127-147 (1989).

11. Ojemann, G. A. Cortical organization of language. J. Neurosci. 11, 2281-2287 (1991).

12. Zatorre, R. J., Meyer, E., Gjedde, A. \& Evans, A. C. PET studies of phonetic processing of speech: Review, replication, and reanalysis. Cereb. Cort. 6, 21-30 (1996).

13. Kuhl, P. K. Learning and representation in speech and language. Curr. Opin. Neurobiol. 4, 812-822 (1994).

14. Klein, D. et al. The neural substrates underlying word generation: A bilingual functional-imaging study. Proc. Natl Acad. Sci. USA 92, 2899-2903 (1995).

15. Steinmetz, H. \& Seitz, R. J. Functional anatomy of language processing: Neuroimaging and the problem of individual variability. Neuropsychologia 29, 1149-1161 (1991).

16. Ogawa, S., Lee, T.-M., Nayak, A. S. \& Glynn, P. Oxygenation-sensitive contrast in magnetic resonance image of rodent brain at high magnetic fields. Magn. Reson. Med. 14, 68-78 (1990).

17. Meyer, K. L. et al. Sensitivity-enhanced echo-planar MRI at $1.5 \mathrm{~T}$ using a $5 \times 5$ mech dome resonator. Magn. Reson. Med. 36, 606-612 (1996).

18. Talairach, J. \& Tournoux, P. Co-planar Stereotaxic Atlas of the Human Brain (Thieme Medical, New York, 1988).

19. Damasio, H. Human Brain Anatomy in Computerized Images (Oxford Univ. Press, New York, 1995).

20. Woods, R. P., Mazziotta, J. C. \& Cherry, S. R. MRI-PET registration with automated algorithm. J. Comput. Assist. Tomogr. 17, 536-546 (1993).

21. Hirsch, J. et al. A multi-stage statistical technique to identify cortical activation using functional MRI. Proc. Soc. Mag. Res. 2, 637 (1994).

22. Hirsch, J. et al. Illusory contours activate specific regions in human visual cortex: Evidence from functional magnetic resonance imaging. Proc. Natl Acad. Sci. USA 92, 6469-6473 (1995).

23. Hinke, R. M. et al. Functional magnetic resonance imaging of Broca's area during internal speech. NeuroReport 4, 675-678 (1993).

24. Oldfield, R. C. The assessment and analysis of handedness: The Edinburgh inventory. Neuropsychologia 9, 97-113 (1971).

Acknowledgements. We thank K. Zakian and D. Ballon for use of the $5 \times 5$ mesh dome resonator, J. Victor, G. Krol, J. Posner, R. Cappiello, M. Ruge, D. Correa, S. Harris, J. Salvagno, P. Kuhl, F. Nottebohm, G. E. Vates and R. DeLePaz for technical assistance and helpful comments, and Y. Popowich, N. Rubin, T. Ozaki, D. R. Moreno, B. Aghazadeh, D. Barbut-Heinemann, D. Orbach, R. Valencia, J. Carton, E. Götte, R. Härtl, O. Torres and M. Li for volunteering as subjects. Supported by the William T. Morris Foundation
R. fellowship, the Tri-Institutional MD/Ph.D Program (KHSK); the Charles A. Dana Foundation, Johnson \& Johnson Focused Giving Foundation, Cancer Center Support Grant NCI (J.H.); the C. V. Starr Foundation and the Lookout Fund (N.R.R.).

Correspondence and requests for materials should be addressed to J. Hirsch (e-mail: hirsch@vision. mskcc.org). 